\title{
Complications of flexible bronchoscopy in children: prospective study of 1,328 procedures
}

\author{
J. de Blic, V. Marchac, P. Scheinmann
}

Complications of flexible bronchoscopy in children: prospective study of 1,328 procedures. J.de Blic, V. Marchac, P. Scheinmann. (C)ERS Journals Ltd 2002.

ABSTRACT: Complications of flexible bronchoscopy (FB) were prospectively evaluated during 1,328 diagnostic procedures in children, not in intensive care units. A total $92.8 \%$ of the procedures were performed in conscious patients under sedation and $7.2 \%$ under deep sedation. Supplementary oxygen was provided in $\sim 80 \%$ of cases via endoscopic face mask $(n=783)$ or nasal prongs $(n=290)$.

At least one complication was recorded in 91 cases $(6.9 \%)$. Minor complications $(n=69 ; 5.2 \%)$ included moderate and transient episodes of desaturation $(n=15)$, isolated excessive coughing $(n=22)$, excessive nausea reflex with coughing $(n=20)$, transient laryngospasm $(n=6)$ and epistaxis $(n=6)$. Major complications $(n=22 ; 1.7 \%)$ included oxygen desaturation to $<90 \%$, either isolated $(\mathrm{n}=10)$ or associated with laryngospasm $(n=6)$, coughing $(n=4)$, bronchospasm $(n=1)$, and pneumothorax $(n=1)$.

Major complications involving oxygen desaturation were associated with age $<2$ yrs (13 of 529 versus 8 of 778) and laryngotracheal abnormalities (7 of 85 versus 14 of 1,222). The overall frequency of complications was similar in conscious $(6.7 \%)$ but sedated patients and patients under deep $(7.3 \%)$ sedation. However, the frequency of transient desaturation was significantly higher in children undergoing FB under deep sedation. Transient fever after bronchoalveolar lavage was observed in 52 of 277 cases $(18.8 \%)$.

Flexible bronchoscopy is a safe procedure with $<2 \%$ major complications. Careful analysis of indications and clinical status for each patient, and proper anaesthesia and monitoring during the examination ensure that the procedure is successful, with a minimum of complications.

Eur Respir J 2002; 20: 1271-1276.

In the last $20 \mathrm{yrs}$, flexible bronchoscopy (FB) has become a major tool for evaluating respiratory disorders in children [1]. The diagnostic value of FB is now widely accepted, it can be used to visualise the lower airways directly and to take samples particularly bronchoalveolar lavage (BAL) which can be performed during the procedure [2].

FB is often considered to be invasive. Many studies have focused on its clinical value but relatively few have dealt with safety and the side-effects of FB in children. Many of these studies are now outdated, and most dealt with small clinical series. The two largest series were published by WooD [3] in 1984, and BARBATO et al. [4] who in 1997, published data from a questionnaire administered in 51 European centres, in which complications were estimated as a percentage of the number of procedures carried out [4].

To identify the principal complications of FB and potential risk factors for complications the FBs performed in the authors unit, between September 1997May 2001, were analysed.

\section{Methods}

All FB procedures from September 1997-May 2001 were analysed prospectively. All FBs performed for therapeutic indications, mostly cases of massive therapeutic lung lavage in children with alveolar proteinosis, were excluded from this study. FBs performed in neonatal or paediatric intensive care units were also excluded, as some procedures were performed in intubated and mechanically ventilated or in critically ill patients.

The data recorded included the patient characteristics, underlying disease, indication, sedation, results, occurrence of side-effects during the procedure and samples taken.

\section{Sedation}

Bronchoscopy was performed in patients under conscious or deep sedation. For conscious sedation, children who had fasted for $4-6 \mathrm{~h}$, were given $0.01 \mathrm{mg} \cdot \mathrm{kg}^{-1}$ sublingual atropine before the procedure. The authors used $2 \%$ lidocaine, to a maximum dose of $7 \mathrm{mg} \cdot \mathrm{kg}^{-1}$, to achieve local anaesthesia of the nose, pharynx and larynx [5]. In infants aged $<3$ months, sedation was achieved with i.v. midazolam alone $\left(75 \mu \mathrm{g} \cdot \mathrm{kg}^{-1}, \mathrm{n}=64\right)$. In older children sedation was achieved with i.v. midazolam alone $\left(150 \mu \mathrm{g} \cdot \mathrm{kg}^{-1} ; \mathrm{n}=481\right)$ or with i.v. midazolam $\left(75 \mu \mathrm{g} \cdot \mathrm{kg}^{-1}\right)$ and inhalation, via an airway endoscopic face mask, of an equimolar 
mixture of nitrous oxide and oxygen $(n=688)$. As the fibroscope was passed into the trachea, lidocaine $(0.5 \%)$ was instilled to achieve anaesthesia of the tracheobronchial mucosa.

Deep sedation was achieved using either volatile (sevoflurane via endoscopic face mask [6]) or intravenous (propofol) agents. The examination was performed with spontaneous ventilation after spraying $5 \%$ lidocaine onto the vocal cords.

All FBs were continuously monitored by pulse oximetry (arterial oxygen saturation $\left.\left(\mathrm{Sa}_{\mathrm{a}} \mathrm{O}_{2}\right)\right)$ and electrocardiography. Procedures were performed in an operating room with all the necessary facilities for resuscitation. The authors selected the bronchoscope diameter (FB type N20, 3C30 and 3C40, or P40; Olympus Winter IBE GMBH, Hamburg, Germany), $2.2,3.6$ or $4.9 \mathrm{~mm}$, according to the age and weight of the child.

The use of an endoscopic face mask, regardless of the sedation used, made it possible to supply 50\% inspiratory oxygen fraction during the procedure. If intravenous midazolam was used alone, supplementary oxygen was provided with nasal prongs in infants weighing $<7 \mathrm{~kg}$ and in children with poor respiratory status.

Nebulised $\beta_{2}$-agonists $\left(0.15 \mathrm{mg} \cdot \mathrm{kg} \quad\right.$ salbutamol $\left.{ }^{-1}\right)$ were administered before the procedure in children with asthma or infants with severe recurrent wheezy bronchitis. Complications recorded during FB were defined as follows. 1) Minor complications: events that did not affect or preclude completion of the procedure. These included epistaxis, moderate and transient episodes of desaturation (no decrease in oxygen saturation to $<90 \%$ and desaturation episodes lasting $<60 \mathrm{~s}$ ), transient laryngospasm, moderate coughing or nausea. 2) Major complications: all events that affected the procedure and required intervention, termination of the procedure in particular. These included pneumothorax, decrease in oxygen saturation to $<90 \%[7,8]$, either isolated or associated with laryngospasm, bronchospasm, coughing.

Complications occurring after FB were also recorded from the patient's medical chart. The occurrence of fever after BAL was recorded for those who were hospitalised in the authors' unit for at least $6 \mathrm{~h}$ after FB (n=277).

\section{Statistical analysis}

Groups were compared using the Mann-Whitney U-test. Variables were analysed by the Chi-squared test using Fisher's exact test. A $\mathrm{p}<0.05$ was considered to be significant.

\section{Results}

\section{Patients}

Between September 1997-May 2001, 1,328 diagnostic FBs were performed in 1,153 children (mean age $4.5 \pm 4.5 \mathrm{yrs}$ (range: 1 month-21 yrs)) at Necker

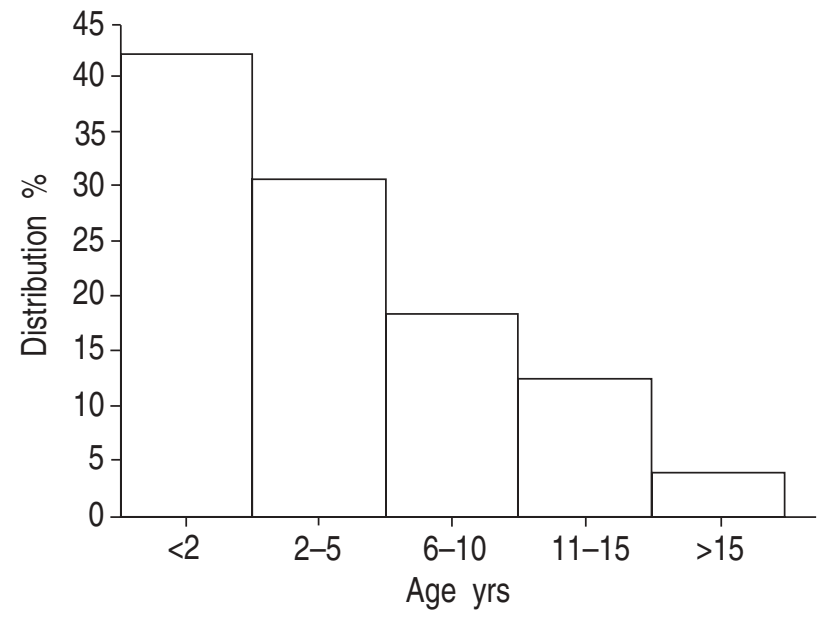

Fig. 1. - Age distribution of the children.

Enfants Malades Hospital in Paris, France. The age distribution of the patients is shown in figure 1. Approximately $40 \%$ of the children were aged $<2$ yrs and $70 \%<5$ yrs. The indications for FB are listed in table 1.

Approximately $60 \%$ of $\mathrm{FB}$ was performed to search for abnormalities in the airways and $7 \%$ were performed in children with interstitial pneumonitis. More than one-half the children had an underlying disease. The main underlying diseases are listed in table 2.

BAL was performed in 578 procedures (43.5\%), and endobronchial biopsies in 76 procedures $(5.7 \%)$.

\section{Sedation}

Most of the procedures $(n=1,233 ; 92.8 \%)$ were performed in conscious patients under sedation.

Table 1.-Indications for flexible bronchocopy

\begin{tabular}{lcc}
\hline Indications & $\mathrm{n}$ & $\%$ \\
\hline $\begin{array}{l}\text { Recurrent or } \\
\quad \text { persistent pneumonia }\end{array}$ & 294 & 22.1 \\
$\begin{array}{l}\text { Recurrent wheezy } \\
\quad \text { bronchitis }\end{array}$ & 204 & 15.4 \\
$\begin{array}{l}\text { Persistent } \\
\quad \text { productive cough }\end{array}$ & 120 & 9.0 \\
$\begin{array}{l}\text { Interstitial pneumonitis } \\
\text { Persistent atelectasis }\end{array}$ & 93 & 7.0 \\
Bronchiectasis & 74 & 5.6 \\
Checking previous bronchoscopy & 68 & 5.1 \\
$\quad$ findings after treatment & 65 & 4.9 \\
Adenopathy & & \\
Acute pneumonia & 51 & 3.8 \\
Localised hyperlucent & 48 & 3.6 \\
$\quad$ lung area & 46 & 3.5 \\
Difficult to treat asthma & & \\
Cough (persistent and & 41 & 3.1 \\
$\quad$ unresponsive to therapy) & 35 & 2.6 \\
Stridor & & \\
Haemoptysis & 33 & 2.5 \\
Persistent wheezing & 27 & 2.0 \\
Suspected foreign body & 26 & 2.0 \\
Miscellaneous & 11 & 0.8 \\
Total & 92 & 7.0 \\
\hline
\end{tabular}


Table 2. - Principal underlying diseases

\begin{tabular}{lcr}
\hline & $\mathrm{n}$ & $\%$ \\
\hline None & 578 & 43.5 \\
Immune deficiencies & 139 & 10.5 \\
Pulmonary tuberculosis & 123 & 9.3 \\
Asthma & 95 & 7.2 \\
Cystic fibrosis & 68 & 5.1 \\
Congenital heart disease & 64 & 4.8 \\
Lung malformations & 61 & 4.6 \\
Bronchopulmonary dysplasia & 61 & 4.6 \\
Vascular ring & 31 & 2.3 \\
\hline
\end{tabular}

Ninety-five procedures were performed under deep sedation. The number of procedures performed under deep sedation increased during the last few months of the survey $\left(<20 \mathrm{yr}^{-1}\right.$ during the first few years and 72 during the last year of the survey).

Supplementary oxygen was provided in $\sim 80 \%$ of cases, via endoscopic face mask $(\mathrm{n}=783)$ or nasal prongs $(n=290)$.

\section{Complications during and after the procedure}

During the procedure. At least one complication was recorded in 91 cases, corresponding to $6.9 \%$ of procedures. Sixty-nine minor complications (5.2\%) and $22(1.7 \%)$ major complications were observed. The complications are described in detail in tables 3 and 4.

Excessive coughing occurred in 26 cases, isolated in 22 cases and associated with oxygen desaturation to $<90 \%$ in four. Laryngospasm was observed in 12 cases, transient in six and severe with oxygen desaturation to $<90 \%$ in six cases.

Oxygen desaturation was observed in 36 cases. Isolated desaturation was recorded in 25 cases, moderate and transient episodes, with $\mathrm{Sa}_{2} \mathrm{O}_{2}$ remaining $<90 \%$ in 15 cases and with $\mathrm{Sa}_{\mathrm{a}} \mathrm{O}_{2}<90 \%$ in 10 cases. The occurrence of isolated oxygen desaturation, regardless of its severity, was not correlated with age, underlying disease, indication, type of sedation or whether or not BAL was performed, but was instead correlated with the presence of laryngotracheal abnormalities $(\mathrm{p}<0.001)$ : laryngomalacia, tracheomalacia, tracheal stenosis. In 11 cases, oxygen desaturation $<90 \%$ was associated with laryngospasm (six cases), cough (four cases) or bronchospasm (one case).

The overall frequency of complications during the procedure was similar in children who were sedated but conscious during FB (6.7\%), and in children in whom FB was performed under deep sedation (7.3\%). However, six cases of moderate and transient desaturation and one case of major desaturation were reported in children undergoing FB under deep sedation. The frequency of transient desaturation was significantly higher in children undergoing FB under deep sedation than in children who were sedated but conscious during FB $(\mathrm{p}<0.001)$.

Analysis of the data for children with major complications showed that $59 \%$ were aged $<2$ yrs, $68 \%$ had an underlying disease and bronchoscopy revealed abnormalities in the anatomy of the larynx or trachea in $32 \%$. Age $<2$ yrs (13 of 529 versus 8 of $778, p=0.049$ ) and laryngotracheal abnormalities (7 of 85 versus 14 of $1,222, p<0.001)$ were significantly associated with major complications involving oxygen desaturation. In contrast, the presence of an underlying disease was not significantly associated with major complications when the whole population was considered. One major complication occurred in children under deep sedation and 21 in children sedated but conscious during FB (NS).

Pneumothorax requiring chest tube insertion for 3 days occurred in one child with bronchiectasis after proximal endobronchial biopsy.

After the procedure. The most frequent complication observed after the procedure was a peak fever, of up to $41{ }^{\circ} \mathrm{C}$, occurring between 4-9 $\mathrm{h}$ after bronchoscopy. Fever was observed after BAL in 52 of 277 cases $(18.8 \%)$. Fever was not associated with the identification of a significant number of bacteria $\left(>10^{4}\right.$

Table 3.-Complications during the procedure

\begin{tabular}{|c|c|c|c|}
\hline & Conscious sedation & Deep sedation & Total \\
\hline Subjects $n$ & 1233 & 95 & 1328 \\
\hline None & $1149(93.2)$ & $88(92)$ & $1237(93.1)$ \\
\hline At least one complication & $84(6.8)$ & $7(7.3)$ & $91(6.9)$ \\
\hline Minor complications & $63(5.1)$ & $6(6.3)$ & $69(5.2)$ \\
\hline Isolated excessive coughing & $22(1.8)$ & 0 & $22(1.7)$ \\
\hline Excessive nausea reflex with coughing & $20(1.6)$ & 0 & $20(1.5)$ \\
\hline Isolated desaturation ${ }^{\#}$ & $9(0.7)$ & $6(6.3)^{* * *}$ & $15(1.1)$ \\
\hline Epistaxis & $6(0.5)$ & 0 & $6(0.5)$ \\
\hline Transient laryngospasm & $6(0.5)$ & 0 & $6(0.5)$ \\
\hline Major complications & $21(1.7)$ & $1(1.0)$ & $22(1.7)$ \\
\hline Important desaturation $^{+}$ & $20(1.6)$ & $1(1.0)$ & $21(1.6)$ \\
\hline Isolated & $9(0.7)$ & $1(1)$ & $10(0.8)$ \\
\hline With laryngospasm & $6(0.5)$ & 0 & $6(0.5)$ \\
\hline With coughing & $4(0.3)$ & 0 & $4(0.3)$ \\
\hline With bronchospasm & $1(0.1)$ & 0 & $1(0.1)$ \\
\hline Pneumothorax & $1(0.1)$ & 0 & $1(0.1)$ \\
\hline
\end{tabular}

Data are presented as $\mathrm{n}(\%) .^{\#}$ : arterial oxygen saturation $\left(\mathrm{Sa}_{\mathrm{a}} \mathrm{O}_{2}\right) \geqslant 90 \%$; ${ }^{\top}$ : without desaturation; ${ }^{+}: S_{\mathrm{a}, \mathrm{O}_{2}}<90 \%$. ***: $\mathrm{p}<0.001$, conscious versus deep sedation. 
Table 4. - Characteristics of children with major complications during procedures $(n=22)$

\begin{tabular}{|c|c|c|c|}
\hline Age & Underlying disease & Indication & Bronchoscopy findings \\
\hline \multicolumn{4}{|l|}{ Isolated } \\
\hline $\begin{array}{l}\text { desaturation }{ }^{+} \\
4 \text { months }\end{array}$ & None & Chronic productive cough & Normal \\
\hline 4 months & $\begin{array}{l}\text { Bronchopulmonary } \\
\text { dysplasia }\end{array}$ & Stridor & Tracheal stenosis \\
\hline 6 months & None & Recurrent wheezy bronchitis & Normal \\
\hline 6 months & None & Recurrent wheezy bronchitis & Normal \\
\hline 9 months & $\begin{array}{l}\text { Bronchopulmonary } \\
\text { dysplasia }\end{array}$ & Recurrent wheezy bronchitis & Normal \\
\hline $2 \mathrm{yrs}$ & Encephalopathy & Recurrent bronchopneumonia & Laryngomalacia \\
\hline 3 yrs & $\begin{array}{l}\text { Bronchopulmonary } \\
\text { dysplasia }\end{array}$ & Recurrent wheezy bronchitis & Normal \\
\hline $6 \mathrm{yrs}$ & None & Persistent pneumonia & Bronchial inflammation \\
\hline $7 \mathrm{yrs}$ & Down's syndrome & Recurrent pneumonia & Laryngomalacia \\
\hline $11 \mathrm{yrs}$ & Asthma & Recurrent pneumonia & Normal \\
\hline \multicolumn{4}{|l|}{$\begin{array}{l}\text { Laryngospasm } \\
\text { with desaturation }\end{array}$} \\
\hline 8 months & $\begin{array}{l}\text { Left pulmonary } \\
\text { artery sling }\end{array}$ & Stridor & Tracheal stenosis \\
\hline $1 \mathrm{yr}$ & $\begin{array}{l}\text { Bone marrow } \\
\text { transplantation }\end{array}$ & Interstitial pneumonitis & $\begin{array}{l}\text { Tracheobronchial } \\
\text { examination not performed }\end{array}$ \\
\hline 3 yrs & None & Persistent pneumonia & $\begin{array}{c}\text { Tracheobronchial } \\
\text { examination not performed }\end{array}$ \\
\hline $4 \mathrm{yrs}$ & $\begin{array}{c}\text { Bronchial } \\
\text { hyperreactivity }\end{array}$ & Persistent pneumonia & Normal \\
\hline $5 \mathrm{yrs}$ & $\begin{array}{c}\text { Bronchial } \\
\text { hyperreactivity }\end{array}$ & Persistent pneumonia & Normal \\
\hline 18 yrs & Heart transplantation & Haemoptysis & Severe tracheomalacia \\
\hline \multicolumn{4}{|l|}{$\begin{array}{l}\text { Coughing with } \\
\text { desaturation }\end{array}$} \\
\hline 4 months & $\begin{array}{l}\text { Bronchopulmonary } \\
\text { dysplasia }\end{array}$ & Unilateral air trapping & Normal \\
\hline 4 months & $\begin{array}{l}\text { Congenital heart } \\
\text { disease }\end{array}$ & Persistent atelectasis & Laryngomalacia \\
\hline 6 months & None & Persistent wheezing & Normal \\
\hline 17 months & Oesophageal atresia & Persistent atelectasis & Severe tracheomalacia \\
\hline \multicolumn{4}{|l|}{$\begin{array}{l}\text { Bronchospasm } \\
\quad \text { with desaturation }\end{array}$} \\
\hline 5 months & $\begin{array}{l}\text { Bronchopulmonary } \\
\text { dysplasia }\end{array}$ & Recurrent atelectasis & $\begin{array}{l}\text { Tracheobronchial } \\
\text { examination not performed }\end{array}$ \\
\hline $\begin{array}{l}\text { Pneumothorax } \\
6 \text { yrs }\end{array}$ & None & Bronchiectasis & Normal \\
\hline
\end{tabular}

${ }^{\#}$ : arterial oxygen saturation $\left(\mathrm{Sa}_{\mathrm{O}} \mathrm{O}_{2}\right)<90 \%, \mathrm{n}=10 ;{ }^{\uparrow}: \mathrm{Sa}_{\mathrm{a}} \mathrm{O}_{2}<90 \%, \mathrm{n}=6{ }^{+}{ }^{+}: S_{\mathrm{a}, \mathrm{O}_{2}}<90 \%, \mathrm{n}=4 ;{ }^{\S}: S_{\mathrm{a}, \mathrm{O}_{2}}<90 \%, \mathrm{n}=1 ;{ }^{f}: \mathrm{n}=1$.

colony forming units $\left.(\mathrm{cfu}) \cdot \mathrm{mL}^{-1}\right)$ in BAL, bronchial inflammation or the occurrence of a complication during the procedure.

Other complications included desaturation $\left(\mathrm{Sa}, \mathrm{O}_{2}\right.$ between $90-95 \%$ ) requiring oxygen supplementation for $<1 \mathrm{~h}(4 \%)$, moderate fever $\left(<38 \cdot 5^{\circ} \mathrm{C}\right)$ without BAL $(1.9 \%)$, and coughing $(0.5 \%)$. Transient desaturation after FB was significantly more frequent in children aged $<2$ yrs $(\mathrm{p}<0.001)$, but was not correlated with desaturation during FB or BAL.

\section{Discussion}

To date, this study is the largest prospective evaluation of the adverse effects of FB in children. Although the population enrolled in this study may appear heterogeneous in terms of age, indications, or underlying disease, it reflects clinical practice in a paediatric respiratory unit. There are no strict definitions of complications during FB. Thus the critera selected, especially the cut-off value of $90 \% \mathrm{Sa}_{\mathrm{a}} \mathrm{O}_{2}$ may appear arbitrary, and brief periods of desaturation to just $<90 \% \quad \mathrm{Sa}_{\mathrm{a}} \mathrm{O}_{2}$ may be considered to constitute a minor complication. However, this criterion has also been used in three other recent publications [6-8]. The present results show that FB is well tolerated in most cases and that the risk of major complications is low. Minor complications were observed in $\sim 5 \%$ of cases and major complications in $<2 \%$. None of the children died during the procedure, and no respiratory deterioration due to bronchoscopy that required intensive care was observed. The results confirm and elaborate on those reported by EBER et al. [9] for 420 procedures $(4.3 \%)$.

In a series of 1,095 procedures published by WooD [3] in 1984, only 32 complications were recorded: four 
major complications (one case of laryngospasm, two of pneumothorax and one of lung abcess), and 28 minor complications (13 cases of transient bradycardia, two of transient laryngospasm, eight of epistaxis and five of anaesthetic complications). However, in the study by Wood [3], the indication for bronchoscopy was evaluation of the upper airways in $47 \%$ of cases, the proportion of immunocompromised children was lower and BAL was performed less frequently, suggesting that the respiratory status of the children was higher. BARBATO et al. [4] have shown that in most centres, the frequency of bleeding, bronchospasm and laryngospasm is $<5 \%$, but oxygen desaturation was not considered to be a specific complication.

Hypoxia is the greatest risk with FB. Various mechanisms may lead to hypoxia. It may be a consequence of laryngospasm, bronchospam or excessive coughing, but the two most likely mechanisms are the partial or total obstruction of the airway by the bronchoscope and depression of the respiratory drive due to sedation. The incidence of desaturation in this series was reduced by the extensive use of oxygen supplementation. The administration of oxygen may have masked possible hypercapnia [6] but end-tidal carbon dioxide was not measured. It has also been reported that i.v. sedation with midazolam and/or the topical application of lidocaine to the upper airways may aggravate laryngomalacia [10], which may in turn favour hypoventilation and hypoxia.

Oxygen desaturation has been reported to be more frequent in very young children than in older patients [11-13]. SCHELlHASE et al. [11] reported transient desaturation in $23 \%$ of infants in whom FB and BAL were performed for severe recurrent wheezing. This frequency is much higher than that reported in this study, probably because oxygen supplementation via nasal prongs was not given systematically to young children in the previous study. The present results are consistent with those reported by SCHNAPF [12]. The greatest decrease in oxygen saturation (mean decrease $11 \%$ ) was observed in the youngest group of patients, aged 6-12 months. In the present study, major complications were more frequent in patients aged $<2$ yrs and in patients with a laryngotracheal abnormality. In contrast, complications were not associated with BAL or with underlying disease.

Other observed complications were laryngospasm, excessive coughing during the procedure and nausea reflex which may be favoured by insufficient local anaesthesia and/or airway reactivity especially in children with known asthma, bronchopulmonary dysplasia, bronchial hyperreactivity or recurrent wheezy bronchitis. The extremely low frequency of bronchospasm (one child with bronchopulmonary dysplasia) probably resulted from the systematic administration of nebulised $\beta_{2}$-agonists before the procedure in asthmatic children [7] and recurrent wheezers.

Sedation may affect the type of complication observed. The overall incidence of complications during FB was similar for procedures performed in conscious children and in children under deep sedation $(6.7 \%$ versus $7.3 \%$ ). However, all complications during deep sedation involved oxygen desaturation, mostly transient, with $\mathrm{Sa}_{\mathrm{a}} \mathrm{O}_{2}$ not falling $<90 \%$. This is consistent with results for other studies [6, 14]. The results show that the risk of desaturation is higher if deep sedation is used, although the use of an endoscopic face mask has probably limited the frequency of desaturation. Indeed, the incidence of complications in the present series is considerably lower than that recently reported by PAYNE et al. [7] in 73 patients undergoing FB under general anaesthesia. The frequency of complications was $24 \%$, with $10 \%$ of patients presenting oxygen desaturation $(>10 \%$ fell below the baseline) and 10\% laryngospasm. This difference may have been due to the more frequent use of muscle relaxant in the study by PAYNE et al. [7].

Transient fever after BAL was the main complication observed after the procedure. It has been suggested that post-FB fever is caused by the BAL-induced release of cytokines from the alveolar cells $[15,16]$. A peak fever (body temperature $>38.5^{\circ} \mathrm{C}$ ) occurred $6-8 \mathrm{~h}$ after the procedure in $18.8 \%$ of cases. This frequency is similar to that observed by SCHELLHASE et al. [17] $(17 \%)$, but is lower than that published by PICARD et al. [18] (48\%). In their study, fever was correlated with positive bacterial culture $\left(>10^{4} \mathrm{cfu} \cdot \mathrm{mL}^{-1}\right)$, age $<2$ yrs and abnormal bronchoscopy findings. This was not the case in the present series. The authors' results may underestimate the incidence of fever because some children returned home on the same day and fever was not assessed in these children. Finally, the spread of infection seems to be a very rare complication of FB. A lung abscess was reported in one case in the series by Wood [3] and no cases were observed in the present series.

Bronchoscopy is a key diagnostic technique in the field of pulmonary pathology and the number of endoscopies performed is continually increasing $[1,4$, 19]. Endoscopies are also increasingly performed in children with more precarious respiratory states. It is therefore essential to maintain a high level of safety. FB can now be performed safely in conscious children under mild sedation [20], but deep sedation is increasingly used, especially for patients with chronic diseases, those undergoing additional procedures and for very anxious, agitated or combative patients. Sedation with the maintenance of spontaneous ventilation ensures successful procedures with the minimum of coughing and laryngospasm.

The present results have a number of practical implications for bronchial endoscopy in children. Much attention should be paid to local anaesthesia, especially if the endoscopy is carried out in sedated but conscious patients, to minimise the risk of laryngospasm. As topical anaesthesia during FB is essential but may alter laryngeal function, NIELSON et al. [10] recommended exploring the larynx before applying topical anaesthesia to the larynx. Similarly, nebulisation of a $\beta_{2}$-agonist should be used to limit the risk of bronchospasm in cases of asthma or bronchial hyperreactivity.

Particular care should be exercised with very young children (aged $<2$ yrs) and children with known or suspected laryngotracheal abnormalities, as these two groups of children have the highest risk of oxygen desaturation. A fibroscope of the smallest possible diameter should be used. The use of flexible bronchoscopes, 
$2.8 \mathrm{~mm}$ in diameter, equipped with a $1.2 \mathrm{~mm}$ diameter suction channel makes it possible to reduce the occluded area by $40 \%$ when compared to a standard paediatric fibroscope $(3.6 \mathrm{~mm}$ in diameter), thereby increasing the tracheal area/fibroscope area ratio. In addition, oxygen supplementation by a face mask or nasal prongs further reduces the risk of oxygen desaturation [12]. Small children also present the highest risk of desaturation in the minutes following the examination. Postbronchoscopy surveillance is therefore necessary to screen for possible oxygen desaturation, which is mostly transient, but may require treatment with oxygen for a few minutes to a few hours.

To conclude, this study shows that flexible bronchoscopy is a safe procedure with a very low incidence, $<2 \%$, of major complications. However, the potentially dangerous nature of these complications necessitates careful analysis of indications and clinical status for each patient and proper monitoring during the procedure. Moreover, the skill of the bronchoscopist may also decrease the incidence of complications, demonstrating the value of training.

\section{References}

1. Nicolai T. Pediatric bronchoscopy. Pediatr Pulmonol 2001; 31: 150-164.

2. de Blic J, Midulla F, Barbato A, et al. Bronchoalveolar lavage in children. ERS Task Force on bronchoalveolar lavage in children. Eur Respir J 2000; 15: 17-34.

3. Wood RE. Spelunking in the pediatric airways: explorations with the flexible fiberoptic bronchoscope. Pediatr Clin North Am 1984; 31: 785-799.

4. Barbato A, Magarotto M, Crivellaro M, et al. Use of the paediatric bronchoscope, flexible and rigid, in 51 European centres. Eur Respir J 1997; 10: 1761-1766.

5. Amitai Y, Zylber-Katz E, Avital A, Zangen D, Noviski N. Serum lidocaine concentrations in children during bronchoscopy with topical anesthesia. Chest 1990; 98: 1370-1373.

6. Erb T, Hammer J, Rutishauser M, Frei FJ. Fibreoptic bronchoscopy in sedated infants facilitated by an airway endoscopy mask. Paediatr Anaesth 1999; 9: 47-52.

7. Payne D, McKenzie SA, Stacey S, Misra D, Haxby E, Bush A. Safety and ethics of bronchoscopy and endobronchial biopsy in difficult asthma. Arch Dis Child 2001; 84: 423-426.
8. Morrow B, Argent A. Risks and complications of nonbronchoscopic bronchoalveolar lavage in a pediatric intensive care unit. Pediatr Pulmonol 2001; 32: 378-384.

9. Eber E, Zach M. Flexible fiberoptic bronchoscopy in pediatrics-an analysis of 420 examinations. Wien Klin Wochenschr 1995; 107: 246-251.

10. Nielson DW, Ku PL, Egger M. Topical lidocaine exaggerates laryngomalacia during flexible bronchoscopy. Am J Respir Crit Care Med 2000; 161: 147151.

11. Schellhase DE, Fawcett DD, Schutze GE, Lensing SY, Tryka AF. Clinical utility of flexible bronchoscopy and bronchoalveolar lavage in young children with recurrent wheezing. J Pediatr 1998; 132: 312-318.

12. Schnapf B. Oxygen desaturation during fiberoptic bronchoscopy in pediatric patients. Chest 1991; 99: 591-594.

13. Gibson NA, Coutts JA, Paton JY. Flexible bronchoscopy under $10 \mathrm{~kg}$. Respir Med 1994; 88: 131-134.

14. Reyle-Hahn M, Niggemann B, Max M, Streich R, Rossaint R. Remifentanil and propofol for sedation in children and young adolescents undergoing diagnostic flexible bronchoscopy. Paediatr Anaesth 2000; 10: 5963.

15. Standiford TJ, Kunkel SL, Strieter RM. Elevated serum levels of tumor necrosis factor-alpha after bronchoscopy and bronchoalveolar lavage. Chest 1991; 99: 1529-1530.

16. Krause A, Hohberg B, Heine F, John M, Bursmester GR, Witt C. Cytokines derived from alveolar macrophages induce fever after bronchoscopy and bronchoalveolar lavage. Am J Respir Crit Care Med 1997; 155: 1793-1797.

17. Schellhase DE, Tamez JR, Menendez AA, Morris MG, Fowler GW, Lensing SY. High fever after flexible bronchoscopy and bronchoalveolar lavage in noncritically ill immunocompetent children. Pediatr Pulmonol 1999; 28: 139-144.

18. Picard E, Schwartz S, Goldberg S, Glick T, Villa Y, Kerem E. A prospective study of fever and bacteremia after flexible fiberoptic bronchoscopy in children. Chest 2000; 117: 573-577.

19. Perez CR, Wood RE. Update on pediatric flexible bronchoscopy. Pediatr Clin North Am 1994; 41: 385400.

20. Tobias J. Sedation and anesthesia for pediatric bronchoscopy. Curr Opin Pediatr 1997; 9: 198-206. 